(C) Elsevier, Paris

\title{
Certain 8-amino-9-(benzyl)guanines as potential purine nucleoside phosphorylase inhibitors
}

\author{
JW Chern ${ }^{*}$, DS Wise1, DS Shewach ${ }^{2}$, PE Daddona ${ }^{3}$, LB Townsend ${ }^{1 * *}$ \\ 'Department of Medicinal Chemistry, College of Pharmacy and Department of Chemistry, The University of Michigan, Ann Arbor, MI, \\ 2 Department of Internal Medicine, The University of Michigan, Ann Arbor, MI; \\ ${ }^{3}$ Department of Biological Chemistry, The University of Michigan, Ann Arbor, MI 48109-1065, USA
}

(Received 12 February 1993; accepted 5 July 1993)

\begin{abstract}
Summary - Several 8-amino-9-(benzyl)guanines were selected for synthesis as potential purine nucleoside phosphorylase (PNP) inhibitors on the basis of the Topliss decision tree. These compounds were prepared by the treatment of oxazolo[ $5,4-d]$ pyrimidine intermediates with potassium carbonate in a 1-pot reaction. All compounds were evaluated for PNP inhibitory activity using an in vitro enzyme inhibition assay. The extent of binding to PNP appeared to be influenced by the presence of electron donating substituents on the phenyl ring of the benzyl group. None of the tested compounds were more active than the parent compound, 8amino-9-benzylguanine. The inhibitory activity seems to be most likely $-\sigma$-dependent.
\end{abstract}

purine nucleoside phosphorylase / structure-activity relationships / enzyme inhibition / 8-aminoguanine / 8-amino-9(benzyl)guanines

\section{Introduction}

Human erythrocytic purine nucleoside phosphorylase (PNP, nucleoside phosphorylase, purine nucleoside, orthophosphate ribosyltransferase, EC 2.4.2.1) is an enzyme in the purine salvage pathway which catalyzes the reversible phosphorolysis of guanosine, inosine, xanthosine, their 2'-deoxyribonucleoside congeners, and many closely related analogs [1]. The development of a PNP inhibitor as a chemotherapeutic target became of interest with the discovery that patients with T-cell-related immunodeficiency diseases demonstrated an associated lack of PNP in their erythrocytes [2]. This rare syndrome suggested that suppression of PNP may result in a selective suppression of cellular immunity which may have therapeutic benefits. For example, a successful PNP inhibitor might be used to treat T-cell leukemia; to counter autoimmune diseases without destroying the patient's humoral immunity; to treat tissue rejection after organ transplantation [3]; or, to treat parasitic diseases [4]. A

*Present address: Medical Laboratories and Institute of Pharmacy, National Defense Medical Center, PO Box 90048512, Taipei, Taiwan, ROC (100).

** Correspondence and reprints number of PNP inhibitors which resemble purine bases or their nucleosides have been identified [5-7]. Among these, 8-aminoguanine $1\left(K_{\mathrm{i}}=0.8 \mu \mathrm{M}\right)$, and 8 -aminoguanosine $2\left(K_{\mathrm{i}}=8 \mu \mathrm{M}\right)$ [8], were the most potent inhibitors of PNP (see fig 1). Cysteine [9], histidine [10] and arginine [11] have been identified and implicated as participants in the catalytic mechanism of mammalian PNP. It has been proposed that the cysteinyl residue protonates the $\mathrm{N}-7$ of the base moiety [12]. The PNP inhibitory activity of 1 and 2 suggested that the C-8 amino group in these inhibitors might act to increase the electron density in the ring system and thus increase the basicity at N-7 for the subsequent protonation by a cysteinyl residue at the active site of PNP. Based on this, we further assumed that the

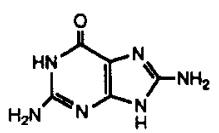

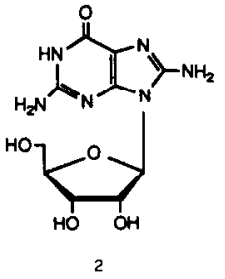

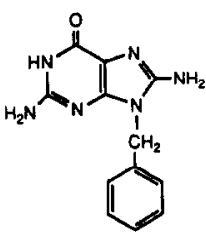

3
Fig 1. Structures of 8-aminoguanine 1, 8-aminoguanosine 2, and 8-amino-9-benzylguanine 3 . 
8-aminoguanine nucleus plays an important role in the recognition and in the binding of the molecule to the active site of the enzyme and that at the active site the heterocycle of guanosine or 8-aminoguanosine most likely occupies a pocket in the enzyme with the ribose moiety oriented exterior to the pocket. To determine if a substituent other than a sugar moiety at N-9 would be recognized by PNP, we prepared 8-amino-9benzylguanine 3, 8-ABG [8], as a potential inhibitor of PNP. Compound 3 was found to be a potent PNP inhibitor with a $K_{\mathrm{i}}$ value of $0.22 \mu \mathrm{M}$, 4-fold more active than 8 -aminoguanine. It has been shown in in vitro experimental studies that 8-ABG potentiates the cytotoxic effect of 2'-deoxyguanosine.

This current study was designed to determine if a substituent on the benzyl ring might possibly maximize the PNP inhibitory activity demonstrated by 3 . To guide our selection of an appropriate electrondonating or withdrawing substituent to place on the phenyl ring, we chose the methodology designed by Topliss [13-15] which allows one to prepare a limited number of derivatives containing substituents which would give good discrimination between hydrophobic $(\sigma)$, electronic $(\pi)$ and steric $\left(E_{\mathrm{s}}\right)$ effects and aid in identifying the class of derivatives with the highest probability of enhanced potency.

\section{Chemistry}

The target compounds were prepared by a multi-step synthesis, as outlined in scheme 1. Treatment of 2-amino-4-chloropyrimidin-6-one 4 with phenyldiazonium chloride furnished 2-amino-4-chloro-5-phenylazopyrimidin-6-one 5 [16]. Condensation of 5 with the appropriate benzylamines afforded a series of 2-amino-4-arylmethylamino-5-phenylazopyrimidin-6ones 6a-f. These compounds were unstable and decomposed on attempts to purify them. However,

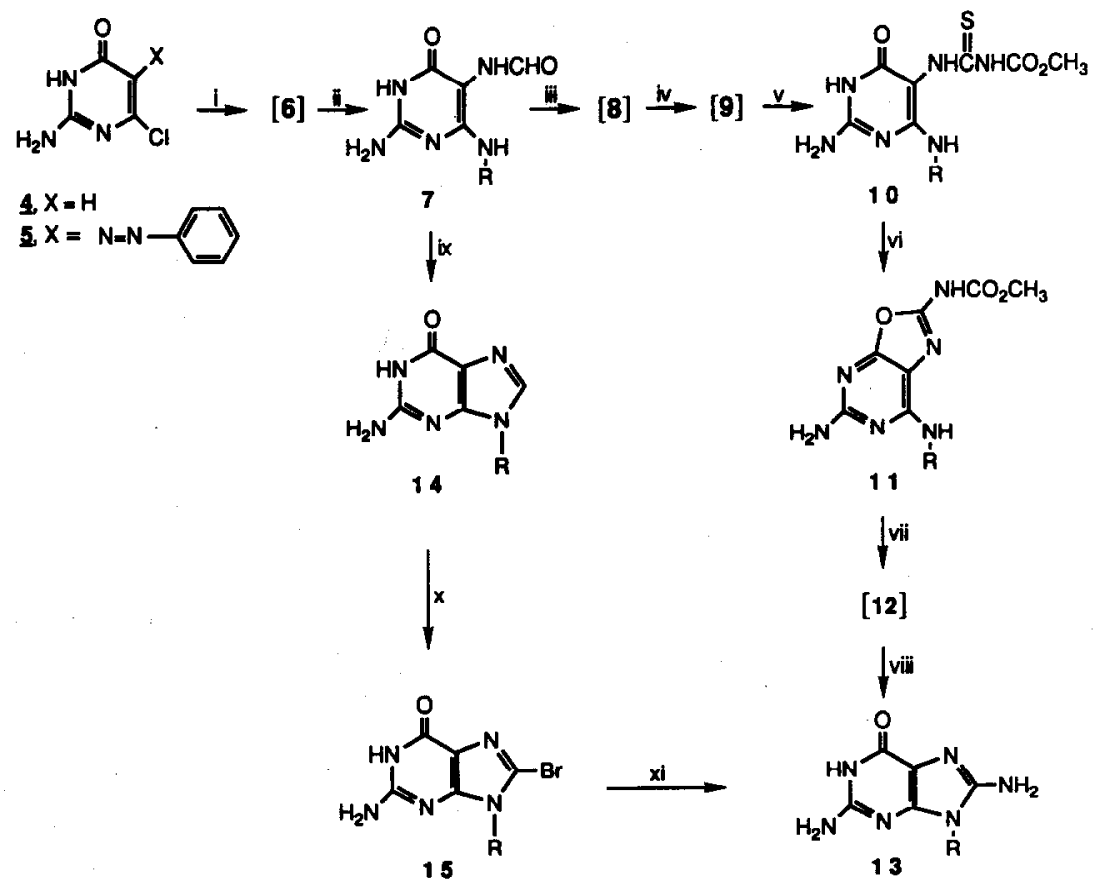

Scheme 1.
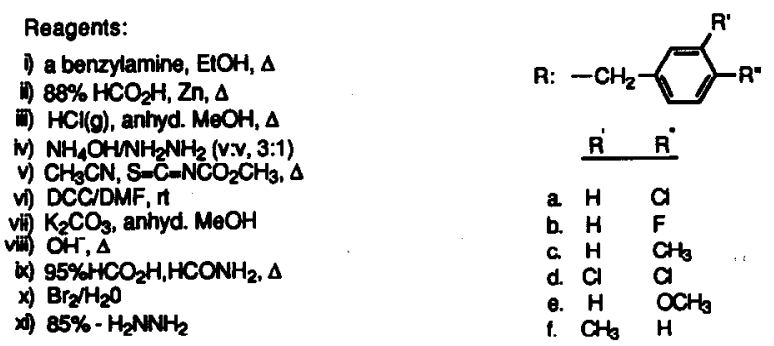
after being washed thoroughly with alcohol and ether, the crude compounds $6 \mathbf{a}-\mathbf{f}$ were observed as a single spot on TLC and were of sufficient purity for the next reaction.

Reductive formylation of the crude 5-diazopyrimidines 6a-f with zinc dust in formic acid [17] gave the 5-formamidopyrimidines $7 \mathbf{a}-\mathbf{f}$ in good yield. The $360-\mathrm{MHz}$ spectra of $7 \mathbf{a}-\mathbf{f}$ in $\mathrm{DMSO}^{-\mathrm{d}_{6}}$ revealed multiple signals for the proton of the 5-formamido group indicating that these compounds most likely exist as a tautomeric pair (both the trans $(E)(70 \%)$ and cis $(Z)(30 \%)$ conformers) similar to previous observations with other $N$-substituted amides [18, 19].

Heating compounds $\mathbf{7 a}-\mathbf{f}$ in methanol saturated with hydrogen chloride at reflux temperature effected deformylation and formation of the hydrochloride salt of the 2,5-diaminopyrimidine derivatives $8 \mathbf{a}-\mathbf{f}$ [20]. Without isolation compounds $\mathbf{8 a}-\mathbf{f}$ were neutralized with ammonium hydroxide and hydrazine $(\mathrm{v} / \mathrm{v}, 3: 1)$ to afford the free bases 9a-f. These derivatives were immediately condensed with methoxycarbonyl isothiocyanate [21] to afford the thiourea derivatives $10 a-f$ in 70 to $88 \%$ overall yield from $7 \mathbf{a}-\mathbf{f}$. Compound 10e was isolated in $31 \%$ yield. Treatment of the thiourea derivatives $10 a-\mathbf{f}$ with dicyclohexylcarbodiimide (DCC) in DMF at room temperature furnished the oxazolo $[5,4-d]$ pyrimidine intermediates 11a-f in good yield. In a 2-step reaction sequence compounds $11 \mathrm{a}-\mathbf{f}$ were treated with 2 equivalents of potassium carbonate to effect a ring opening and rearrangement to give the 8-methoxycarbamoylguanines 12a-f. TLC analysis indicated that the products $12 a-f$ were accompanied by a small amount of the 8-aminoguanine derivatives 13a-f. As a result of this contamination, the derivatives 12a-f were not isolated but were converted directly to $13 a-f$ by removal of the reaction solvent in vacuo followed by suspension in water and heating the mixture at reflux for $24 \mathrm{~h}$. The reaction mixture was then neutralized with glacial acetic acid to obtain the target 8-aminoguanines 13a-f in good yield. This approach provided a clean reaction with a relatively easy isolation and purification of the target compounds 13a-f. Compound 13a was also prepared in a more conventional manner. In this procedure, compound $7 \mathbf{a}$ was cyclized by treatment with formic acid and formamide to furnish the guanine 14a. Treatment of $14 a$ with saturated bromine water solution afforded 8-bromo-9-( $p$-chlorobenzyl)guanine 15a in good yield [22]. However, when 15a was treated at reflux with aqueous hydrazine [23], 8-amino-9-( $p$-chlorobenzyl)guanine 13a was obtained in only $24 \%$ yield.

\section{Biological activity}

The 8-amino-9-(benzyl)guanine derivatives 13a-f were evaluated for PNP inhibitory activity using an
Table I. Inhibition constants of some 8-amino-9-(benzyl)guanines for purine nucleoside phosphorylase from $\mathrm{T}$ lymphoblasts.

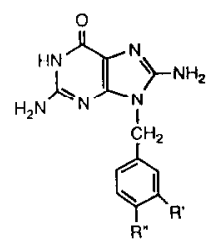

\begin{tabular}{lccc}
\hline & & \multicolumn{2}{c}{ Rank order } \\
\cline { 2 - 4 } Compd & $K_{i}(\mu M)$ & Obsdc & Calcdc for $-\sigma$ \\
\hline 13d 3,4-Cl & $>100(2)$ & 5 & 5 \\
13a 4-Cl & $3.06(2)^{\mathrm{a}}$ & 4 & 4 \\
13c 4-CH & $1.22(2)$ & 3 & 2 \\
13e 4-OCH & $0.74(2)$ & 2 & 1 \\
3 & $0.22(2)$ & 1 & 3 \\
8-Aminoguanosine & $7.0 \pm 3^{\mathrm{b}}(4)$ & & \\
Second compound group & & \\
13f 3-CH & $1.67(2)$ & & \\
13b 4-F & $1.11(2)$ & \\
\hline
\end{tabular}

aNumbers in parentheses, number of experimental determinations of each kinetic constant; bmean $\pm S D$; csee $[13,14]$.

in vitro enzyme inhibition assay [9]. Double reciprocal plots of the initial velocity data indicated that these compounds inhibited PNP in a competitive manner (with respect to inosine). $K_{\mathrm{i}}$ values were estimated from a replot of the slopes versus inhibitor concentrations. These results have been summarized in table I. None of these derivatives showed an increase in inhibitory activity of PNP over the parent benzyl derivative 3 with a $K_{\mathrm{i}}$ value of $0.22 \mu \mathrm{M}$. However, all of the derivatives except 13d were superior PNP inhibitors compared to 8-aminoguanosine $\left(K_{\mathrm{i}}=8 \mu \mathrm{M}\right)$. The selection of the substituents on the benzyl ring was made based upon the Topliss selection tree [13-15]. No obvious correlation between substituent and activity could be delineated from this study. The $p$-chloro derivative 13a was found to be 10 -fold less potent than compound 3 , thus indicating a possible unfavorable effect from a para substituent for steric reasons, or that the decreased activity is a result of $-\sigma$ or $-\pi$ effects by the $4-\mathrm{Cl}$ substituent. That the effect 
is not enhanced by $+\pi$ or $+\sigma$ substitution is apparent from the total lack of inhibition of PNP by the 3,4dichlorobenzyl derivative $13 \mathrm{~d}$. The 4 -methoxybenzyl derivative 13e, a second-tier derivative on the Topliss tree, was more active than the 4-chlorobenzyl compound 13a. This observation supported the preparation of other compounds which possess a $-\sigma$ effect, and, on this basis the 3-methylbenzyl derivative 13f and 4-fluorobenzyl derivative 13b were prepared. Although these compounds were active, neither demonstrated increased activity compared to 3 . Thus, although a number of the $-\sigma$-directed derivatives of 3 demonstrated potent inhibition of PNP, a definitive structure-activity relationship due to these changes was not apparent. It can be concluded from this study that the 8-aminoguanine nucleus must play the primary role in binding the molecule to the active site and that the enzyme can tolerate a bulky group such as a benzyl group at N-9. Substituents on the benzyl moiety are well tolerated and do not affect, significantly, the activity demonstrated by this class of compounds.

\section{Experimental protocols}

\section{General methods}

Melting points were determined using a Thomas-Hoover capillary melting apparatus and are uncorrected. ${ }^{1} \mathrm{H}-\mathrm{NMR}$ spectra were obtained at $360 \mathrm{MHz}$ using a Bruker Wm 360 spectrometer. The chemical shifts are reported in ppm $(\delta)$ downfield from internal $\mathrm{Me}_{4} \mathrm{Si}$. IR spectra were recorded using a Perkin-Elmer Model 281 infrared spectrophotometer and the values are expressed in $\mathrm{cm}^{-1}$. Analytical samples were dried at $78^{\circ} \mathrm{C}$ in the presence of $\mathrm{P}_{2} \mathrm{O}_{5}$ for at least $12 \mathrm{~h}$. TLC was performed on silica-gel GHLF TLC plates (250 microns) and were visualized by UV. Microanalyses were performed by $\mathrm{M}-\mathrm{H}-\mathrm{W}$ Laboratories, Phoenix, AZ. All compounds were analyzed for $\mathrm{C}, \mathrm{H}, \mathrm{N}$. Analytical results were within $\pm 0.4 \%$ of the theoretical values.

\section{2-Amino-4-(p-chlorobenzyl)amino-5-formamidopyrimidin-6- one $7 a$}

4-Chlorobenzylamine $(3.0 \mathrm{ml}, 25 \mathrm{mmol})$ was added to a suspension of 2-amino-4-chloro-5-phenylazopyrimidin-6-one 5 [10] $(5.0 \mathrm{~g}, 20 \mathrm{mmol})$ in absolute EtOH $(50 \mathrm{ml})$. The mixture was heated at reflux in an oil bath for $6 \mathrm{~h}$. Water $(100 \mathrm{ml})$ was added to the mixture and after standing at $25^{\circ} \mathrm{C}$ for $18 \mathrm{~h}$ the solid which had formed was collected by filtration, washed with $\mathrm{H}_{2} \mathrm{O}(5 \mathrm{ml})$ and then ether $(15 \mathrm{ml})$ to furnish 2-amino-4(p-chlorobenzyl)amino-5-phenylazopyrimidin-6-one $6 \mathrm{a}(5.7 \mathrm{~g}$, $91 \%)$. To a mixture of crude $6 a$ in $88 \%$ formic acid $(40 \mathrm{ml})$ was added zinc dust in small portions until the initially orangecolored mixture became colorless. The mixture was heated on a steam bath for $30 \mathrm{~min}$, filtered and washed with $88 \%$ formic acid $(10 \mathrm{ml})$. Upon addition of $\mathrm{H}_{2} \mathrm{O}(100 \mathrm{ml})$ to the filtrate, a solid formed which was collected by filtration, washed first with $\mathrm{H}_{2} \mathrm{O}(15 \mathrm{ml})$, and then with ether $(10 \mathrm{ml})$ to afford compound 7a. Recrystallization from a mixture of $\mathrm{EtOH}$ and $\mathrm{H}_{2} \mathrm{O}(\mathrm{v}: \mathrm{v}, 1: 1)$ gave pure compound $7 \mathrm{a}(2.83 \mathrm{~g}, 82 \%)$, mp:
270-271 ${ }^{\circ} \mathrm{C}$; UV $\lambda_{\max } \mathrm{nm}\left(\varepsilon \times 10^{4}\right):(\mathrm{MeOH}) 275(1.5) ;(\mathrm{pH} 1)$ 272 (1.9); (pH 11 ) 267 (1.4). 'H-NMR (DMSO-d ${ }_{6}$ ): isomer A: $(60 \%), \delta 4.43$ (pseudotriplet, $2 \mathrm{H}, \mathrm{CH}_{2}$ ), $6.25\left(\mathrm{~s}, 2 \mathrm{H}, \mathrm{NH}_{2}\right), 6.65$ (t, 1H, NH), 7.30 (m, 4H, Ar-H), 8.03 (s, 1H, CHO), 8.49 (s, $1 \mathrm{H}, \mathrm{NH}$ ), 10.02 (s, $1 \mathrm{H}, \mathrm{NH}$ ); isomer B: $(40 \%), \delta, 4.43$ (pseudotriplet, $\left.2 \mathrm{H}, \mathrm{CH}_{2}\right), 6.33\left(\mathrm{~s}, 2 \mathrm{H}, \mathrm{NH}_{2}\right), 6.97(\mathrm{t}, 1 \mathrm{H}, \mathrm{NH}), 7.30(\mathrm{~m}$, $4 \mathrm{H}, \mathrm{Ar}-\mathrm{H}$ ), 7.70 (d, 1H, CHO), 7.90 (d, 1H, NH), 10.02 (s, 1H, $\mathrm{NH})$. Anal $\mathrm{C}_{12} \mathrm{H}_{12} \mathrm{CIN}_{5} \mathrm{O}_{2}(\mathrm{C}, \mathrm{H}, \mathrm{N})$.

\section{2-Amino-4-(p-fluorobenzyl)amino-5-formamidopyrimidin-6-} one $7 b$

Compound $7 \mathrm{~b}$ was prepared in $42 \%$ yield using a procedure similar to that which afforded compound 7a. An analytical sample was prepared by recrystallization from a mixture of DMF and water (v:v, 1:1), mp: $242-244^{\circ} \mathrm{C}$; IR (KBr): 3500 , $3340,1700-1570,1480,1390,1220,815,760 \mathrm{~cm}^{-1}$. ${ }^{1} \mathrm{H}-\mathrm{NMR}$ $\left(360 \mathrm{MHz}, \mathrm{DMSO} \mathrm{d}_{6}\right.$ ): isomer A: $(60 \%), \delta 4.45$ (pseudotriplet, $\left.2 \mathrm{H}, \mathrm{CH}_{2}\right), 6.29\left(\mathrm{~s}, 2 \mathrm{H}, \mathrm{NH}_{2}\right), 6.65(\mathrm{t}, 1 \mathrm{H}, \mathrm{NH}), 7.07-7.12(\mathrm{~m}$, $2 \mathrm{H}, \mathrm{Ar}-\mathrm{H}), 7.30-7.33(\mathrm{~m}, 2 \mathrm{H}, \mathrm{Ar}-\mathrm{H}), 8.05(\mathrm{~s}, 1 \mathrm{H}, \mathrm{CHO}), 8.51$ $(\mathrm{s}, 1 \mathrm{H}, \mathrm{NH}), 10.05(\mathrm{~s}, 1 \mathrm{H}, \mathrm{NH})$; isomer $\mathrm{B}:(40 \%), \delta 4.45$ (pseudotriplet, $\left.2 \mathrm{H}, \mathrm{CH}_{2}\right), 6.37\left(\mathrm{~s}, 2 \mathrm{H}, \mathrm{NH}_{2}\right), 6.97(\mathrm{t}, 1 \mathrm{H}, \mathrm{NH})$, 7.07-7.12 (m, 2H, Ar-H), 7.30-7.33 (m, 2H, Ar-H), 7.72 (d, $1 \mathrm{H}, J=11.6 \mathrm{~Hz}, \mathrm{CHO}), 7.92(\mathrm{~d}, 1 \mathrm{H}, J=11.6 \mathrm{~Hz}, \mathrm{NH}), 10.06$ (s, $1 \mathrm{H}, \mathrm{NH})$. Anal $\mathrm{C}_{12} \mathrm{H}_{12} \mathrm{FN}_{5} \mathrm{O}_{2}(\mathrm{C}, \mathrm{H}, \mathrm{N})$.

2-Amino-4-(p-methylbenzyl)amino-5-formamidopyrimidin-6one $7 \mathrm{c}$

Compound $7 \mathrm{c}$ was prepared in $71 \%$ yield using a procedure similar to that which afforded compound 7a. An analytical sample was prepared by recrystallization from a mixture of MeOH and $\mathrm{H}_{2} \mathrm{O}$ (v:v, $1: 1$ ), mp: $253-254^{\circ} \mathrm{C}$; IR (KBr): 3480 , $3420,3320,3000,2910,2730,1680-1580,1490,1380,1340$, $1180,1100,760 \mathrm{~cm}^{-1} .{ }^{1} \mathrm{H}-\mathrm{NMR}$ (DMSO-d $\left.\mathrm{d}_{6}\right)$ : isomer A: $(60 \%)$, $\delta 2.24$ (s, 3H, $\mathrm{CH}_{3}$ ), 4.41 (pseudotriplet, $2 \mathrm{H}, \mathrm{CH}_{2}$ ), 6.24 (s, $2 \mathrm{H}$, $\left.\mathrm{NH}_{2}\right), 6.52(\mathrm{t}, 1 \mathrm{H}, \mathrm{NH}), 7.08(\mathrm{~m}, 2 \mathrm{H}, \mathrm{Ar}-\mathrm{H}), 7.16(\mathrm{~m}, 2 \mathrm{H}, \mathrm{Ar}-$ $\mathrm{H}), 8.03(\mathrm{~s}, 1 \mathrm{H}, \mathrm{CHO}), 8.40(\mathrm{~s}, 1 \mathrm{H}, \mathrm{NH}), 10.01(\mathrm{~s}, 1 \mathrm{H}, \mathrm{NH})$ : isomer B: $(40 \%), \delta 2.24\left(\mathrm{~s}, 3 \mathrm{H}, \mathrm{CH}_{3}\right), 4.41$ (pseudotriplet, $2 \mathrm{H}$, $\left.\mathrm{CH}_{2}\right), 6.32$ (s, 2H, $\mathrm{NH}_{2}$ ), $6.84(\mathrm{t}, 1 \mathrm{H}, \mathrm{NH}), 7.08(\mathrm{~m}, 2 \mathrm{H}, \mathrm{Ar}-\mathrm{H})$, $7.16(\mathrm{~m}, 2 \mathrm{H}, \mathrm{Ar}-\mathrm{H}), 7.70(\mathrm{~d}, 1 \mathrm{H}, J=11.2 \mathrm{~Hz}, \mathrm{CHO}), 7.88(\mathrm{~d}$, $1 \mathrm{H}, J=11.2 \mathrm{~Hz}, \mathrm{NH}), 10.01(\mathrm{~s}, 1 \mathrm{H}, \mathrm{NH})$. Anal $\mathrm{C}_{13} \mathrm{H}_{15} \mathrm{~N}_{5} \mathrm{O}_{2} \bullet 1 / 3$ $\mathrm{H}_{2} \mathrm{O}(\mathrm{C}, \mathrm{H}, \mathrm{N})$.

2-Amino-4-(3,4-dichlorobenzyl)amino-5-formamidopyrimidin6-one $7 d$

Compound $7 \mathrm{~d}$ was prepared in $69 \%$ yield using a procedure similar to that which afforded compound $7 a$. An analytical sample was prepared by recrystallization from a mixture of DMF and water (v:v, 1:1), mp: $264-265^{\circ} \mathrm{C}$; IR (KBr): 3500 , $3350,3080,2880,2740,1715,1690-1570,1390,1130,1030$, $765 \mathrm{~cm}^{-1}$. ${ }^{1} \mathrm{H}-\mathrm{NMR}$ (DMSO-d $\mathrm{d}_{6}$ ): isomer A: $(60 \%), \delta 4.43$ (pseudotriplet, $\left.2 \mathrm{H}, \mathrm{CH}_{2}\right), 6.27\left(\mathrm{~s}, 2 \mathrm{H}, \mathrm{NH}_{2}\right), 6.70(\mathrm{t}, 1 \mathrm{H}, \mathrm{NH})$, $7.22(\mathrm{~d}, 1 \mathrm{H}, \mathrm{Ar}-\mathrm{H}), 7.50-7.55(\mathrm{~m}, 2 \mathrm{H}, \mathrm{Ar}-\mathrm{H}), 8.05(\mathrm{~s}, 1 \mathrm{H}$, $\mathrm{CHO}), 8.53(\mathrm{~s}, 1 \mathrm{H}, \mathrm{NH}), 10.07(\mathrm{~s}, 1 \mathrm{H}, \mathrm{NH})$ : isomer $\mathrm{B}:(40 \%)$, $\delta 4.43$ (pseudotriplet, $\left.2 \mathrm{H}, \mathrm{CH}_{2}\right), 6.36\left(\mathrm{~s}, 2 \mathrm{H}, \mathrm{NH}_{2}\right), 7.03(\mathrm{t}, 1 \mathrm{H}$, $\mathrm{NH}), 7.22(\mathrm{~d}, 1 \mathrm{H}, \mathrm{Ar}-\mathrm{H}), 7.50-7.55(\mathrm{~m}, 2 \mathrm{H}, \mathrm{Ar}-\mathrm{H}), 7.71(\mathrm{~d}$, $1 \mathrm{H}, J=11.2 \mathrm{~Hz}, \mathrm{CHO}), 7.93(\mathrm{~d}, 1 \mathrm{H}, J=11.2 \mathrm{~Hz}, \mathrm{NH}), 10.07$ (s, $1 \mathrm{H}, \mathrm{NH}$ ). Anal $\mathrm{C}_{12} \mathrm{H}_{11} \mathrm{Cl}_{2} \mathrm{~N}_{5} \mathrm{O}_{2}(\mathrm{C}, \mathrm{H}, \mathrm{N})$.

2-Amino-4-(4-methoxybenzyl)amino-5-formamidopyrimidin-6one $7 e$

Compound $7 \mathrm{e}$ was prepared in $81 \%$ yield using a procedure similar to that which afforded compound 7a. An analytical sample was prepared by recrystallization from a mixture of DMF and water (v:v, 1:1), mp: $256-257^{\circ} \mathrm{C}$; IR (KBr): 3370 , $3210,3070,2910,2780,1705,1660,1640,1580,1510,1240$, $1175,1030 \mathrm{~cm}^{-1}$. ${ }^{1} \mathrm{H}-\mathrm{NMR}\left(\mathrm{DMSO}_{\mathrm{C}}\right): 3.71\left(\mathrm{~s}, 3 \mathrm{H}, \mathrm{OCH}_{3}\right)$, 
4.40 (d, 2H, $\left.\mathrm{CH}_{2}\right), 6.30$ (s, $\left.2 \mathrm{H}, \mathrm{NH}_{2}\right), 6.37\left(\mathrm{~s}, 2 \mathrm{H}, \mathrm{NH}_{2}\right), 6.54$ $(\mathrm{t}, \mathrm{H}, \mathrm{NH}), 6.85(\mathrm{~d}, 2 \mathrm{H}, J=8.2 \mathrm{~Hz}), 7.21(\mathrm{~d}, 2 \mathrm{H}, J=7.54 \mathrm{~Hz})$, $7.72(\mathrm{~d}, 1 \mathrm{H}, J=12 \mathrm{~Hz}), 7.91(\mathrm{~d}, 1 \mathrm{H}, J=12 \mathrm{~Hz}), 8.05(\mathrm{~s}, 1 \mathrm{H}$, $\mathrm{CHO}), 8.51(\mathrm{~s}, 1 \mathrm{H}, \mathrm{CHO}) ; 10.07(\mathrm{~s}, 1 \mathrm{H}, \mathrm{NH})$. Anal $\mathrm{C}_{13} \mathrm{H}_{15} \mathrm{~N}_{5} \mathrm{O}_{3}$ $(\mathrm{C}, \mathrm{H}, \mathrm{N})$.

2-Amino-4-(p-chlorobenzyl)amino-5-[1-(3-methoxycarbonyl)thioureidolpyrimidin-6-one 10a

A suspension of $7 \mathbf{a}(2.0 \mathrm{~g}, 6.81 \mathrm{mmol})$ in anhydrous $\mathrm{MeOH}$ $(30 \mathrm{ml})$ was heated at reflux while dry $\mathrm{HCl}$ was passed through the mixture. The mixture became a solution within a few min and then became a suspension again. After $2 \mathrm{~h}$ heating, the mixture was cooled in an ice bath for $30 \mathrm{~min}$. The solid was collected by filtration, washed with anhydrous ether $(10 \mathrm{ml})$ and air dried for $6 \mathrm{~h}$ to obtain 2,5-diamino-4-( $p$-chlorobenzyl)aminopyrimidin-6-one hydrochloride $8 \mathrm{a}(1.75 \mathrm{~g}, 77 \%)$. This crude product 8 a was suspended in $\mathrm{H}_{2} \mathrm{O}(30 \mathrm{ml})$ and the $\mathrm{pH}$ of the mixture was adjusted to 8 with a mixture of aqueous $\mathrm{NH}_{4} \mathrm{OH}$ and hydrazine (v:v, 3:1). The mixture was stirred at rt for $1 \mathrm{~h}$, then the white solid was collected by filtration and washed with $\mathrm{H}_{2} \mathrm{O}(5 \mathrm{ml})$. The solid was then mixed with 3 equivalents of methoxycarbonyl isothiocyanate (prepared by adding methyl chloroformate dropwise to a suspension of potassium thiocyanate in acetonitrile) and water $(10 \mathrm{ml})$. This mixture was heated at reflux for $5 \mathrm{~h}$. The mixture was cooled to $\mathrm{rt}$, the solid collected by filtration and then washed with water $(20 \mathrm{ml})$ to furnish $10 \mathrm{a}(1.89 \mathrm{~g}, 73 \%)$. An analytical sample was prepared by recrystallization from a mixture of $\mathrm{DMF}$ and water (v:v, 1:1), mp: $248-250^{\circ} \mathrm{C}$; IR (KBr): 3500, 3400, 3320, 3180, $3020,2950,2840,2700,1740,1670,1640,1590,1490,1240$, $1190,1045 \mathrm{~cm}^{-1}$; UV $\lambda_{\max } \mathrm{nm}\left(\varepsilon \times 10^{4}\right):(\mathrm{MeOH} / \mathrm{DMF}, \mathrm{v}: \mathrm{v}$, 9:1) 268 (2.3); (pH 1) 278 (2.7); (pH 11) 267 (2.4); ${ }^{1} \mathrm{H}-\mathrm{NMR}$ (DMSO-d $\left.{ }_{6}\right):$ d $3.70\left(\mathrm{~s}, 3 \mathrm{H}, \mathrm{CH}_{3}\right), 4.45\left(\mathrm{~d}, 2 \mathrm{H}, \mathrm{CH}_{2}\right), 6.32$ $\left(\mathrm{s}, 2 \mathrm{H}, \mathrm{NH}_{2}\right), 6.92(\mathrm{t}, 1 \mathrm{H}, \mathrm{NH}), 7.33(\mathrm{q}, 4 \mathrm{H}, \mathrm{Ar}-\mathrm{H}), 10.04$ $(\mathrm{s}, 1 \mathrm{H}, \mathrm{NH}), 10.13(\mathrm{~s}, 1 \mathrm{H}, \mathrm{NH}), 11.19(\mathrm{~s}, 1 \mathrm{H}, \mathrm{NH})$. Anal $\mathrm{C}_{14} \mathrm{H}_{15} \mathrm{ClN}_{6} \mathrm{O}_{3} \mathrm{~S}(\mathrm{C}, \mathrm{H}, \mathrm{N})$.

2-Amino-4-(p-fluorobenzyl)amino-5-[1-(3-methoxycarbonyl)thioureidolpyrimidin-6-one $\mathbf{1 0 b}$

Compound 10b was prepared in $72 \%$ yield using a procedure similar to that which afforded 10a. An analytical sample was prepared by recrystallization from a mixture of $\mathrm{DMF} / \mathrm{H}_{2} \mathrm{O}$ (v:v, 1:9), mp: $244-245^{\circ} \mathrm{C}$; IR (KBr): $3510,3390,3330,3200,2860$ $2700,1740,1660,1645,1590,1500,1255,1190,1040 \mathrm{~cm}^{-1}$; UV $\lambda_{\max } \mathrm{nm}\left(\varepsilon \times 10^{4}\right):(\mathrm{MeOH} / \mathrm{DMF}, \mathrm{v}: \mathrm{v}, 9: 1) 266(2.3)$; $(\mathrm{pH}$ 1) 266 (2.5); (pH 11) 266 (2.3). ${ }^{1} \mathrm{H}-\mathrm{NMR}\left(\mathrm{DMSO}-\mathrm{d}_{6}\right): \delta 3.69$ $\left(\mathrm{s}, 3 \mathrm{H}, \mathrm{OCH}_{3}\right), 4.44\left(\mathrm{~d}, 2 \mathrm{H}, J=5.7 \mathrm{~Hz}, \mathrm{CH}_{2}\right), 6.31(\mathrm{~s}, 2 \mathrm{H}$, $\left.\mathrm{NH}_{2}\right), 6.89(\mathrm{t}, 1 \mathrm{H}, \mathrm{NH}), 7.07(\mathrm{t}, 2 \mathrm{H}, \mathrm{Ar}-\mathrm{H}), 7.36(\mathrm{q}, 2 \mathrm{H}, \mathrm{Ar}-\mathrm{H})$, $10.03(\mathrm{~s}, 1 \mathrm{H}, \mathrm{NH}), 10.12(\mathrm{~s}, 1 \mathrm{H}, \mathrm{NH}), 11.17(\mathrm{~s}, 1 \mathrm{H}, \mathrm{NH})$. Anal $\mathrm{C}_{14} \mathrm{H}_{15} \mathrm{FN}_{6} \mathrm{O}_{3} \mathrm{~S}(\mathrm{C}, \mathrm{H}, \mathrm{N})$.

2-Amino-4-(p-methylbenzyl)amino-5-[1-(3-methoxycarbonyl)thioureido]pyrimidin-6-one 10c

Compound 10c was prepared in $75 \%$ yield using a procedure similar to that which afforded 10a. An analytical sample was prepared by recrystallization from a mixture of $\mathrm{DMF} / \mathrm{H}_{2} \mathrm{O}$ (v:v, 1:3), mp: 250-251 ${ }^{\circ} \mathrm{C}$; IR (KBr): 3500, 3390, 3340, $3230,3180,3020,2720,1740,1660,1640,1345,1235,1190$, $1050 \mathrm{~cm}^{-1}$; UV $\lambda_{\text {max }} \mathrm{nm}\left(\varepsilon \times 10^{4}\right):(\mathrm{MeOH} / \mathrm{DMF}, \mathrm{v}: \mathrm{v}, 9: 1) 268$ (2.3); (pH 1) 268 (2.7); (pH 11) 267 (2.3); ${ }^{1}$ H-NMR $\left(\mathrm{DMSO}-\mathrm{d}_{6}\right)$ : d $2.25\left(\mathrm{~s}, 3 \mathrm{H}, \mathrm{CH}_{3}\right), 3.70\left(\mathrm{~s}, 3 \mathrm{H}, \mathrm{OCH}_{3}\right), 4.43(\mathrm{~d}$, $\left.2 \mathrm{H}, J=5.7 \mathrm{~Hz}, \mathrm{CH}_{2}\right), 6.30\left(\mathrm{~s}, 2 \mathrm{H}, \mathrm{NH}_{2}\right), 6.83(\mathrm{t}, 1 \mathrm{H}, \mathrm{NH}), 7.07$ (d, $2 \mathrm{H}, J=7.8 \mathrm{~Hz}, \mathrm{Ar}-\mathrm{H}), 7.20(\mathrm{~d}, 2 \mathrm{H}, J=7.8 \mathrm{~Hz}, \mathrm{Ar}-\mathrm{H})$, 10.01 (s, 1H, NH), 10.12 (s, 1H, NH), 11.17 (s, 1H, NH). Anal $\mathrm{C}_{15} \mathrm{H}_{18} \mathrm{~N}_{6} \mathrm{O}_{3} \mathrm{~S}(\mathrm{C}, \mathrm{H}, \mathrm{N})$.
2-Amino-4-(3,4-dichlorobenzyl)amino-5-[1-(3-methoxycarbonyl)thioureidolpyrimidin-6-one 10d

Compound 10d was prepared in $85 \%$ yield using a procedure similar to that which afforded 10d. An analytical sample was prepared by recrystallization from a mixture of $\mathrm{DMF} / \mathrm{H}_{2} \mathrm{O}(\mathrm{v}: \mathrm{v}$, $1: 1), \mathrm{mp} ; 247-248^{\circ} \mathrm{C}$; ${ }^{1} \mathrm{H}-\mathrm{NMR}$ (DMSO-d $): \delta 3.70(\mathrm{~s}, 3 \mathrm{H}$, $\left.\mathrm{OCH}_{3}\right), 4.45\left(\mathrm{~d}, 2 \mathrm{H}, \mathrm{CH}_{2}\right), 6.32\left(\mathrm{~s}, 2 \mathrm{H}, \mathrm{NH}_{2}\right), 6.64(\mathrm{~s}, 1 \mathrm{H}, \mathrm{Ar}-$ $\mathrm{H}), 6.96(\mathrm{t}, 1 \mathrm{H}, \mathrm{NH}), 7.29(\mathrm{~d}, 1 \mathrm{H}, J=8.2 \mathrm{~Hz}, \mathrm{Ar}-\mathrm{H}), 7.51(\mathrm{~d}$, $1 \mathrm{H}, J=8.2 \mathrm{~Hz}, \mathrm{Ar}-\mathrm{H}), 10.07(\mathrm{~s}, 1 \mathrm{H}, \mathrm{NH}), 10.13(\mathrm{~s}, 1 \mathrm{H}, \mathrm{NH})$, $11.22(\mathrm{~s}, 1 \mathrm{H}, \mathrm{NH})$. Anal $\mathrm{C}_{14} \mathrm{H}_{14} \mathrm{Cl}_{2} \mathrm{~N}_{6} \mathrm{O}_{3} \mathrm{~S}(\mathrm{C}, \mathrm{H}, \mathrm{N})$.

2-Amino-4-(p-methoxybenzyl)amino-5-[1-(3-methoxycarbonyl)thioureidolpyrimidin-6-one 10e

Compound 10e was prepared in $31 \%$ yield using a procedure similar to that which afforded 10a. An analytical sample was prepared by recrystallization from a mixture of $D M F / \mathrm{H}_{2} \mathrm{O}(\mathrm{v}: \mathrm{v}$, 1:3), mp: $234-235^{\circ} \mathrm{C}$; IR (KBr): $3480,3380,3370,3200,3020$, $2950,2840,2700,1745,1660,1640,1580,1550,1500,1390$, 1340, $1050 \mathrm{~cm}^{-1}$; UV $\lambda_{\max }$ nm $\left(\varepsilon \times 10^{4}\right):(\mathrm{MeOH} / \mathrm{DMF}, \mathrm{v}: \mathrm{v}$, 9:1) 269 (2.3); (pH 1) 268 (2.7); (pH 11) 267 (2.4); ${ }^{1}$ H-NMR $\left(\mathrm{DMSO}-\mathrm{d}_{6}\right)$ : d $3.68\left(\mathrm{~s}, 3 \mathrm{H}, \mathrm{OCH}_{3}\right), 3.69\left(\mathrm{~s}, 3 \mathrm{H}, \mathrm{CH}_{3}\right), 4.40(\mathrm{~d}$, $\left.2 \mathrm{H}, \mathrm{CH}_{2}\right), 6.30\left(\mathrm{~s}, 2 \mathrm{H}, \mathrm{NH}_{2}\right), 6.77(\mathrm{t}, 1 \mathrm{H}, \mathrm{NH}), 6.81(\mathrm{~d}, 2 \mathrm{H}, J=$ $8.6 \mathrm{~Hz}, \mathrm{Ar}-\mathrm{H}), 7.23(\mathrm{~d}, 2 \mathrm{H}, J=8.6 \mathrm{~Hz}, \mathrm{Ar}-\mathrm{H}), 10.00(\mathrm{~s}, 1 \mathrm{H}$, $\mathrm{NH}), 10.11(\mathrm{~s}, 1 \mathrm{H}, \mathrm{NH}), 11.14(\mathrm{~s}, 1 \mathrm{H}, \mathrm{NH})$. Anal $\mathrm{C}_{15} \mathrm{H}_{18} \mathrm{~N}_{6} \mathrm{O}_{4} \mathrm{~S}$ $(\mathrm{C}, \mathrm{H}, \mathrm{N})$.

2-Amino-4-(m-methylbenzyl)amino-5-[1-(3-methoxycarbonyl)thioureidolpyrimidin-6-one 10f

Compound 10f was prepared from 5 without isolation of the intermediates $\mathbf{6 f}$ and 7f. 3-Methylbenzylamine $(1.5 \mathrm{ml}$, $12 \mathrm{mmol})$ was added to a suspension of $5(2.84 \mathrm{~g}, 10 \mathrm{mmol})$ in absolute $\mathrm{EtOH}(50 \mathrm{ml})$. The mixture was heated at reflux for $6 \mathrm{~h}$ then water $(100 \mathrm{ml})$ was added. After standing at it for $18 \mathrm{~h}$ the solid was collected, washed with $\mathrm{H}_{2} \mathrm{O}(10 \mathrm{ml})$ and ether ( $15 \mathrm{ml}$ ) to give crude 6f. Without further purification $\mathrm{Zn}$ dust was added to a suspension of $6 f$ in $88 \%$ formic acid until the solution became colorless. After filtration to remove the unreacted $\mathrm{Zn}$, water $(100 \mathrm{ml})$ was added to the filtrate. The resulting solid $7 f$ was collected and washed with water $(15 \mathrm{ml})$ then ether $(10 \mathrm{ml})$. Crude $7 \mathrm{f}$ was converted to compound $10 \mathrm{f}$ in $88 \%$ yield using a procedure similar to that which afforded 10a. An analytical sample was prepared by recrystallization from a mixture of DMF/ $\mathrm{H}_{2} \mathrm{O}(\mathrm{v}: \mathrm{v}, 1: 3)$, mp: $254-256^{\circ} \mathrm{C}$; IR (KBr): $3505,3400,3315,3210,3190,3010,2950,2900,2700$, $1740,1660,1640,1500,1390,1340,1250,1190,1045 \mathrm{~cm}^{-1}$; UV $\lambda_{\max } \mathrm{nm}\left(\varepsilon \times 10^{4}\right):(\mathrm{MeOH} / \mathrm{DMF}, \mathrm{v}: \mathrm{v}, 9: 1) 267(2.4) ;(\mathrm{pH}$ 1) $267(2.7)$; (pH 11) 266 (2.4); 1H-NMR (DMSO-d 1 $_{6}$ : d 2.29 (s, 3H, $\left.\mathrm{CH}_{3}\right), 3.70\left(\mathrm{~s}, 3 \mathrm{H}, \mathrm{CH}_{3}\right), 4.45\left(\mathrm{~d}, 2 \mathrm{H}, \mathrm{CH}_{2}\right), 6.33(\mathrm{~s}, 2 \mathrm{H}$, $\left.\mathrm{NH}_{2}\right), 6.93-6.96(\mathrm{~m}, 3 \mathrm{H}, \mathrm{Ar}-\mathrm{H}+\mathrm{NH}), 7.07-7.17(\mathrm{~m}, 2 \mathrm{H}, \mathrm{Ar}-$ $\mathrm{H}), 10.03(\mathrm{~s}, 1 \mathrm{H}, \mathrm{NH}), 10.14(\mathrm{~s}, 1 \mathrm{H}, \mathrm{NH}), 11.20(\mathrm{~s}, 1 \mathrm{H}, \mathrm{NH})$. Anal $\mathrm{C}_{15} \mathrm{H}_{18} \mathrm{~N}_{6} \mathrm{O}_{3} \mathrm{~S}(\mathrm{C}, \mathrm{H}, \mathrm{N})$.

Methyl 6-amino-4-(p-chlorobenzyl)aminooxazolo[5,4-d]pyrimidine-2-carbamate IIa

A mixture of $10 \mathrm{a}(1.85 \mathrm{~g}, 4.83 \mathrm{mmol})$ and dicyclohexylcarbodiimide $(3.0 \mathrm{~g}, 14.56 \mathrm{mmol})$ in DMF $(30 \mathrm{ml})$ was allowed to stir at $\mathrm{rt}$ until all of the starting material had reacted $(\approx 48 \mathrm{~h})$. The solvent was evaporated in vacuo (oil pump) at $60^{\circ} \mathrm{C}$ to afford a residual solid which was suspended in boiling toluene $(25 \mathrm{ml})$ and stirred for $30 \mathrm{~min}$. The solid which formed was collected by filtration from the hot mixture, washed with boiling toluene $(50 \mathrm{ml})$ and then ether $(10 \mathrm{ml})$ to afford $11 \mathrm{a}$ $(1.5 \mathrm{~g}, 89 \%)$. An analytical sample was prepared by recrystallization from a mixture of $\mathrm{DMF} / \mathrm{H}_{2} \mathrm{O}$ (v:v, 3:7), mp: 289$290^{\circ} \mathrm{C}$; IR (KBr): $3500,3420,3200,3100,2950,2860,1770$, $1730,1670-1660,1460,1360,1300,1215,1070,1015 \mathrm{~cm}^{-1}$; 
UV $\lambda_{\max } \mathrm{nm}\left(\varepsilon \times 10^{4}\right):(\mathrm{MeOH}) 284$ (2.1); (pH 1) 268 (2.1), 306 (1.4); (pH 11) 298 (2.4); ${ }^{1}$ H-NMR (DMSO-d $)$ ) d 3.69 (s, $3 \mathrm{H}, \mathrm{CH}_{3}$ ), 4.57 (brs, 2H, $\mathrm{CH}_{2}$ ), 6.22 (s, 2H, $\mathrm{NH}_{2}$ ), 7.34 (s, 4H, Ar-H), 7.97 (br s, $1 \mathrm{H}, \mathrm{NH}$ ). Anal $\mathrm{C}_{14} \mathrm{H}_{13} \mathrm{ClN}_{6} \mathrm{O}_{3}(\mathrm{C}, \mathrm{H}, \mathrm{N})$.

Methyl 6-amino-4-(p-fluorobenzyl)aminooxazolo[5,4-d]pyrimidine-2-carbamate $\mathbf{I l b}$

Compound 11b was prepared in $80 \%$ yield using a procedure similar to that which afforded 11a. An analytical sample was prepared by recrystallization from a mixture of $\mathrm{DMF} / \mathrm{H}_{2} \mathrm{O}(\mathrm{v}: \mathrm{v}$, 2:8), mp: $278-280^{\circ} \mathrm{C}\left(210^{\circ} \mathrm{C}\right.$ changed color); IR (Kr): 3940 , $3420,3310,3190,3080,2950,1770,1740,1670,1650-1600$, $1510,1470,1350,1320,1230,1070,780,755 \mathrm{~cm}^{-1}$; UV $\lambda_{\max }$ nm ( $\left.\varepsilon \times 10^{4}\right)$ : (MeOH) 284 (2.0); (pH 1) 268 (2.1), 306 (1.3); (pH 11) $298(2.2) ;{ }^{1} \mathrm{H}-\mathrm{NMK}\left(\mathrm{DMSO}-\mathrm{d}_{6}\right): \delta 3.69\left(\mathrm{~s}, 3 \mathrm{H}, \mathrm{CH}_{3}\right)$, 4.57 (brs, $\left.2 \mathrm{H}, \mathrm{CH}_{2}\right), 6.22\left(\mathrm{~s}, 2 \mathrm{H}, \mathrm{NH}_{2}\right), 7.10(\mathrm{t}, 2 \mathrm{H}, \mathrm{Ar}-\mathrm{H}), 7.37$ (q, 2H, Ar-H), 7.94 (br s, 1H, NH), 11.03 (s, 1H, NH). Anal $\mathrm{C}_{14} \mathrm{H}_{13} \mathrm{FN}_{6} \mathrm{O}_{3} \cdot 1 / 4 \mathrm{H}_{2} \mathrm{O}(\mathrm{C}, \mathrm{H}, \mathrm{N})$.

Methyl 6-amino-4-(p-methylhenzyl)aminonxazolo[5,4-d]pyrimidine-2-carbamate IIc

Compound 11c was prepared in $87 \%$ yield using a procedure similar to that which afforded 11a. An analytical sample was prepared by recrystallization from a mixture of DMF/ $\mathrm{H}_{2} \mathrm{O}(\mathrm{v}: \mathrm{v}$, 2:8), mp: $280-281^{\circ} \mathrm{C}$; IR (KBr): $3500,3340,3310,3220,3010$, $2960,2860,1730,1670,1730,1610,1465,1445,1335$, $1065 \mathrm{~cm}^{-1}$; UV $\lambda_{\max } \mathrm{nm}\left(\varepsilon \times 10^{4}\right):(\mathrm{MeOH}) 284(2.0) ;(\mathrm{pH} 1)$ 268 (2.0), 305 (1.3); (pH 11) 298 (2.2); ${ }^{1} \mathrm{H}-\mathrm{NMR}$ (DMSO-d 6 ): $\delta 2.24\left(\mathrm{~s}, 3 \mathrm{H}, \mathrm{CH}_{3}\right), 3.72\left(\mathrm{~s}, 3 \mathrm{H}, \mathrm{OCH}_{3}\right), 4.55$ (brs, $\left.2 \mathrm{H}, \mathrm{CH}_{2}\right)$, $6.20\left(\mathrm{~s}, 2 \mathrm{H}, \mathrm{NH}_{2}\right), 7.08(\mathrm{~d}, 2 \mathrm{H}, J=7.9 \mathrm{~Hz}, \mathrm{Ar}-\mathrm{H}), 7.20$ (d, $2 \mathrm{H}$, $J=7.9 \mathrm{~Hz}, \mathrm{Ar}-\mathrm{H}), 7.87$ (br s, $1 \mathrm{H}, \mathrm{NH}), 11.01(\mathrm{~s}, 1 \mathrm{H}, \mathrm{NH})$. Anal $\mathrm{C}_{15} \mathrm{H}_{16} \mathrm{~N}_{6} \mathrm{O}_{3}(\mathrm{C}, \mathrm{H}, \mathrm{N})$.

Methyl 6-amino-4-(3,4-dichlorobenzyl)aminooxazolo[5,4-d]pyrimidine-2-carbamate 11d

Compound 11d was prepared in $87 \%$ yield using a procedure similar to that which afforded 11a. An analytical sample was prepared by recrystallization from a mixture of DMF/ $\mathrm{H}_{2} \mathrm{O}(\mathrm{v}: \mathrm{v}$, 3:7), mp: $294-295^{\circ} \mathrm{C}$; IR (KBr): $3500,3310,3210,2870,1725$, $1665,1610,1360,1060 \mathrm{~cm}^{-1}$; UV $\lambda_{\max } \mathrm{nm}\left(\varepsilon \times 10^{4}\right):(\mathrm{MeOH})$ 284 (2.1); (pH 1) 267 (2.1), 307 (1.4); (pH 11) 299 (2.4); ${ }^{1} \mathrm{H}-\mathrm{NMR}$ (DMSO-d $\mathrm{d}_{6}$ ) d 3.69 (s, 3H, $\mathrm{OCH}_{3}$ ), 4.57 (brs, $2 \mathrm{H}$, $\left.\mathrm{CH}_{2}\right), 6.26\left(\mathrm{~s}, 2 \mathrm{H}, \mathrm{NH}_{2}\right), 7.32$ (d, $\left.1 \mathrm{H}, J=8.4 \mathrm{~Hz}, \mathrm{Ar}-\mathrm{H}\right), 7.53$ (s, 1H, Ar-H), 7.56 (s, 1H, Ar-H), 8.00 (br s, 1H, NH), 11.07 (s, $1 \mathrm{H}, \mathrm{NH}$ ). Anal $\mathrm{C}_{14} \mathrm{H}_{12} \mathrm{Cl}_{2} \mathrm{~N}_{6} \mathrm{O}_{3}(\mathrm{C}, \mathrm{H}, \mathrm{N})$.

Methyl 6-amino-4-(p-methoxybenzyl)aminooxazolo[5,4-d]pyrimidine-2-carbamate Ile

Compound 11e was prepared in $84 \%$ yield using a procedure similar to that which afforded 11a. An analytical sample was prepared by recrystallization from a mixture of $\mathrm{DMF} / \mathrm{H}_{2} \mathrm{O}(\mathrm{v}: \mathrm{v}$, 3:7), mp: $284-285^{\circ} \mathrm{C}$; IR (KBr): $3500,3320,3200,3010,2960$, $2860,1725,16701610,1510,1470,1440,1350,1240$, $1070 \mathrm{~cm}^{-1}$; UV $\lambda_{\max } \mathrm{nm}\left(\varepsilon \times 10^{4}\right):(\mathrm{MeOH}) 283(2.1) ;(\mathrm{pH} 1)$ 268 (2.0), 306 (1.3); (pH 11) 298 (2.1); 1 H-NMR (DMSO-d d $^{\text {) }}$ :

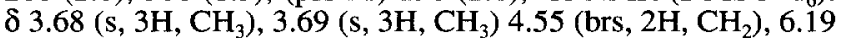
$\left(\mathrm{s}, 2 \mathrm{H}, \mathrm{NH}_{2}\right), 6.84(\mathrm{~d}, 2 \mathrm{H}, J=8.4 \mathrm{~Hz}, \mathrm{Ar}-\mathrm{H}), 7.26(\mathrm{~d}, 2 \mathrm{H}, J=$ $8.4 \mathrm{~Hz}, \mathrm{Ar}-\mathrm{H}), 7.83$ (br s, $1 \mathrm{H}, \mathrm{NH}), 11.00$ (s, 1H, NH). Anal $\mathrm{C}_{15} \mathrm{H}_{16} \mathrm{~N}_{6} \mathrm{O}_{4}(\mathrm{C}, \mathrm{H}, \mathrm{N})$.

Methyl 6-amino-4-(m-methylbenzyl)aminooxazolo[5,4-d]pyrimidine-2-carbamate $11 f$

Compound 11f was prepared in $87 \%$ yield using a procedure similar to that which afforded 11a. An analytical sample was prepared by recrystallization from a mixture of methanol/ $\mathrm{H}_{2} \mathrm{O}$ (v:v, 3:7), mp: $274-275^{\circ} \mathrm{C}$; IR (KBr): $3500,3415,3185,2955$, $1720,1665,1640,1620,1460,1440,1340,1080 \mathrm{~cm}^{-1}$; UV $\lambda_{\max } \mathrm{nm}\left(\varepsilon \times 10^{4}\right):(\mathrm{McOH}) 283(2.1) ;(\mathrm{pH} \mathrm{1}) 268$ (2.2), 306 (1.4); (pH 11) 299 (2.4); ${ }^{1} \mathrm{H}-\mathrm{NMR}$ (DMSO-d $\mathrm{d}_{6}$ ): $\delta 2.25(\mathrm{~s}, 3 \mathrm{H}$, $\mathrm{CH}_{3}$ ), 3.69 (s, 3H, $\mathrm{OCH}_{3}$ ), 4.56 (brs, $\left.2 \mathrm{H}, \mathrm{CH}_{2}\right), 6.21$ (s, 2H, $\left.\mathrm{NH}_{2}\right), 7.00-7.18(\mathrm{~m}, 4 \mathrm{H}, \mathrm{Ar}-\mathrm{H}), 7.87$ (br s, $\left.1 \mathrm{H}, \mathrm{NH}\right), 11.02(\mathrm{~s}$, $1 \mathrm{H}, \mathrm{NH})$. Anal $\mathrm{C}_{15} \mathrm{H}_{16} \mathrm{~N}_{6} \mathrm{O}_{3}(\mathrm{C}, \mathrm{H}, \mathrm{N})$.

\section{8-Amino-9-(p-chlorobenzyl)guanine 13a}

Method 1. A mixture of $11 \mathrm{a}(0.60 \mathrm{~g}, 1.7 \mathrm{mmol})$ and $\mathrm{K}_{2} \mathrm{CO}_{3}$ $(0.5 \mathrm{~g}, 3.6 \mathrm{mmol})$ in anhydrous $\mathrm{MeOH}(20 \mathrm{ml})$ was heated at reflux for $4 \mathrm{~h}$. The mixture was evaporated to dryness in vacuo (oil pump) at $60^{\circ} \mathrm{C}$ and the residue was dissolved in $\mathrm{H}_{2} \mathrm{O}$ $(30 \mathrm{ml})$. The solution was heated at reflux for $48 \mathrm{~h}$. The mixture was cooled to $\mathrm{rt}$ and the $\mathrm{pH}$ adjusted to 5 with glacial acetic acid. The solid was collected by filtration and washed with $\mathrm{H}_{2} \mathrm{O}(50 \mathrm{ml})$. The crude product was dissolved in $0.1 \mathrm{~N}$ aqueous $\mathrm{NaOH}$ and reprecipitated with glacial acetic acid to give pure 13a $(0.43 \mathrm{~g}, 82 \%), \mathrm{mp}:>300^{\circ} \mathrm{C}$; UV $\lambda_{\max } \mathrm{nm}(\varepsilon \times$ 104): (methanol/DMF, v:v, 9:1) 294 (1.0); (pH 1) 289 (1.0); $(\mathrm{pH} 11) 257$ (1.5), $274(1.4) ;{ }^{1} \mathrm{H}-\mathrm{NMR}$ (DMSO-d $\left.{ }_{6}\right): \delta 5.03(\mathrm{~s}$, $\left.2 \mathrm{H}, \mathrm{CH}_{2}\right), 5.99\left(\mathrm{~s}, 2 \mathrm{H}, \mathrm{NH}_{2}\right), 6.25\left(\mathrm{~s}, 2 \mathrm{H}, \mathrm{NH}_{2}\right), 7.39$ (d, $2 \mathrm{H}$, $J=8.4 \mathrm{~Hz}, \mathrm{Ar}-\mathrm{H}), 7.19(\mathrm{~d}, 2 \mathrm{H}, J=8.4 \mathrm{~Hz}, \mathrm{Ar}-\mathrm{H}), 10.59(\mathrm{~s}, 1 \mathrm{H}$, $\mathrm{NH})$. Anal $\mathrm{C}_{12} \mathrm{H}_{11} \mathrm{ClN}_{6} \mathrm{O}(\mathrm{C}, \mathrm{H}, \mathrm{N})$.

Method 2. A mixture of $15 \mathrm{a}(0.7 \mathrm{~g}, 1.97 \mathrm{mmol})$ and $85 \%$ hydrazine $(30 \mathrm{ml})$ was heated at reflux, After $12 \mathrm{~h}$, the mixture had become a fine suspension. After $48 \mathrm{~h}$, the mixture was cooled to $\mathrm{rt}$, the solid was collected by filtration and washed first with $\mathrm{H}_{2} \mathrm{O}(10 \mathrm{ml})$ and then $\mathrm{MeOH}(10 \mathrm{ml})$. The crude product was recrystallized from a mixture of $\mathrm{DMF} / \mathrm{MeOH}(\mathrm{v}: \mathrm{v}$, $1: 1)$ to furnish $13 \mathrm{a}(0.14 \mathrm{~g}, 24 \%)$. This material was identical in all respects to 13a prepared in Method 1.

\section{8-Amino-9-(p-fluorobenzyl)guanine $13 b$}

A mixture of $11 \mathrm{~b}(0.57 \mathrm{~g}, 1.7 \mathrm{mmol})$ and $\mathrm{K}_{2} \mathrm{CO}_{3}(0.5 \mathrm{~g}$, $3.6 \mathrm{mmol})$ in anhydrous $\mathrm{MeOH}(20 \mathrm{ml})$ was heated at reflux for $4 \mathrm{~h}$. The mixture was evaporated to dryness in vacuo (oil pump) at $60^{\circ} \mathrm{C}$ and the residue was dissolved in $\mathrm{H}_{2} \mathrm{O}$ $(30 \mathrm{ml})$. The solution was heated at reflux for $48 \mathrm{~h}$. The mixture was cooled to $\mathrm{rt}$ and the $\mathrm{pH}$ adjusted to 5 with glacial acetic acid. The solid was collected by filtration and washed with $\mathrm{H}_{2} \mathrm{O}(50 \mathrm{ml})$. The crude product was dissolved in $0.1 \mathrm{~N}$ aqueous $\mathrm{NaOH}$ and reprecipitated with glacial acetic acid to give pure $13 \mathrm{~b}(0.39 \mathrm{~g}, 82 \%)$, $\mathrm{mp}:>300^{\circ} \mathrm{C}$; IR (KBr): 3490 , $3300,3140,2900,2750,1690,1630,1610,1560,1510,1370$, $1220 \mathrm{~cm}^{-1}$; UV $\lambda_{\max } \mathrm{nm}\left(\varepsilon \times 10^{4}\right):(\mathrm{MeOH} / \mathrm{DMF}, \mathrm{v}: \mathrm{v}, 1: 1) 292$ (0.8); (pH 1) 254 (1.4), 288 (0.9); (pH 11) 263 (1.2), 270 (1.2); ${ }^{\mathrm{I}} \mathrm{H}-\mathrm{NMR}\left(\mathrm{DMSO}-\mathrm{d}_{6}\right): \delta 5.01\left(\mathrm{~s}, 2 \mathrm{H}, \mathrm{CH}_{2}\right), 6.05\left(\mathrm{~s}, 2 \mathrm{H}, \mathrm{NH}_{2}\right)$, $6.31\left(\mathrm{~s}, 2 \mathrm{H}, \mathrm{NH}_{2}\right), 7.50(\mathrm{t}, 2 \mathrm{H}, \mathrm{Ar}-\mathrm{H}), 7.22(\mathrm{q}, 2 \mathrm{H}, \mathrm{Ar}-\mathrm{H})$, $10.76(\mathrm{~s}, 1 \mathrm{H}, \mathrm{NH})$. Anal $\mathrm{C}_{12} \mathrm{H}_{11} \mathrm{FN}_{6} \mathrm{O}(\mathrm{C}, \mathrm{H}, \mathrm{N})$.

\section{8-Amino-9-(p-methylbenzyl)guanine 13c}

A mixture of 11c $(0.94 \mathrm{~g}, 2.86 \mathrm{mmol})$ and $\mathrm{K}_{2} \mathrm{CO}_{3}(0.79 \mathrm{~g}$, $5.7 \mathrm{mmol})$ in anhydrous $\mathrm{MeOH}(30 \mathrm{ml})$ was heated at reflux temperature for $4 \mathrm{~h}$. The mixture was evaporated to dryness in vacuo (oil pump) at $60^{\circ} \mathrm{C}$ and the resulting solid was dissolved in $\mathrm{H}_{2} \mathrm{O}(30 \mathrm{ml})$. Adjusting the $\mathrm{pH}$ of the mixture to 7 with glacial acetic acid effected the precipitation of a solid which was collected by filtration and washed with $\mathrm{H}_{2} \mathrm{O}(20 \mathrm{ml})$ to obtain a crude product which contained 12c as the major product and $13 \mathrm{c}$ as the minor product. These crude products were treated with $\mathrm{NaOH}(0.9 \mathrm{~g}, 22.5 \mathrm{mmol})$ in $\mathrm{H}_{2} \mathrm{O}(30 \mathrm{ml})$ and the mixture was heated at reflux for $48 \mathrm{~h}$. The $\mathrm{pH}$ of the mixture was adjusted to 7 with glacial acetic acid and the resulting solid was collected by filtration and washed with $\mathrm{H}_{2} \mathrm{O}$ $(20 \mathrm{ml})$ to afford pure $13 \mathrm{c}(0.56 \mathrm{~g}, 79 \%), \mathrm{mp}:>300^{\circ} \mathrm{C}$; IR $(\mathrm{KBr}): 3480,3380,3290,3140,3020,2890,2720,1690,1640$, 
$1630,1610,1560,1460,1410,1370 \mathrm{~cm}^{-1}$; UV $\lambda_{\max } \mathrm{nm}(\varepsilon \mathrm{x}$ 104): (MeOH/DMF, v:v, 9:1) 262 (1.3), 294 (0.8); (pH 1) 254 (1.3) 289 (1.0); (pH 11) 261 (1.2), 272 (1.2). ${ }^{1}$ H-NMR $\left(\mathrm{DMSO}-\mathrm{d}_{6}\right): \delta 2.24\left(\mathrm{~s}, 3 \mathrm{H}, \mathrm{CH}_{3}\right), 4.98\left(\mathrm{~s}, 2 \mathrm{H}, \mathrm{CH}_{2}\right), 6.02(\mathrm{~s}$, $\left.2 \mathrm{H}, \mathrm{NH}_{2}\right), 7.08(\mathrm{q}, 4 \mathrm{H}, \mathrm{Ar}-\mathrm{H}), 10.83$ (s, 1H, NH). Anal $\mathrm{C}_{13} \mathrm{H}_{14} \mathrm{~N}_{6} \mathrm{O} \cdot 1 / 2 \mathrm{H}_{2} \mathrm{O}(\mathrm{C}, \mathrm{H}, \mathrm{N})$.

\section{8-Amino-9-(3,4-dichlorobenzyl)guanine 13d}

Compound 13d was prepared in $81 \%$ yield using a procedure similar to that which afforded $13 \mathrm{c}$. An analytical sample was prepared by recrystallization from a mixture of $D M F / \mathrm{H}_{2} \mathrm{O}(\mathrm{v}: \mathrm{v}$, 1:1), mp: > 300 ${ }^{\circ} \mathrm{C}$; IR (KBr): 3480, 3300, 3160, 2880, 2840, $2740,1705,1690,1630,1565,1465,1390,1300 \mathrm{~cm}^{-1}$; UV $\lambda_{\max } \mathrm{nm}\left(\varepsilon \times 10^{4}\right):(\mathrm{MeOH} / \mathrm{DMF}, \mathrm{v}: \mathrm{v}, 9: 1) 264(1.2), 281(0.7)$, 294 (0.8); (pH 1) 255 (1.5); (pH 11) 260 (1.3), 272 (1.1); ${ }^{1} \mathrm{H}-\mathrm{NMR}$ (DMSO-d $\left.\mathrm{d}_{6}\right): \delta 5.03\left(\mathrm{~s}, 2 \mathrm{H}, \mathrm{CH}_{2}\right), 6.09\left(\mathrm{~s}, 2 \mathrm{H}, \mathrm{NH}_{2}\right.$ ), $6.32\left(\mathrm{~s}, 2 \mathrm{H}, \mathrm{NH}_{2}\right), 7.12$ (dd, $1 \mathrm{H}, J=1.98 \mathrm{~Hz}, J=8.32 \mathrm{~Hz}, \mathrm{Ar}-$ $\mathrm{H}), 7.44(\mathrm{~d}, 1 \mathrm{H}, J=1.95 \mathrm{~Hz}, \mathrm{Ar}-\mathrm{H}), 7.59(\mathrm{~d}, 1 \mathrm{H}, J=8.31 \mathrm{~Hz}$, Ar-H), 10.75 (s, 1H, NH). Anal $\mathrm{C}_{12} \mathrm{H}_{11} \mathrm{Cl}_{2} \mathrm{~N}_{6} \mathrm{O}(\mathrm{C}, \mathrm{H}, \mathrm{N})$.

\section{8-Amino-9-(p-methoxybenzyl)guanine $13 e$}

Compound 13e was prepared in $84 \%$ yield using a procedure similar to that which afforded $13 \mathrm{c}$. An analytical sample was prepared by dissolving a sample in $0.1 \mathrm{~N}$ aqueous $\mathrm{NaOH}$ and reprecipitating with glacial acetic acid, mp: $>300^{\circ} \mathrm{C}$; UV $\lambda_{\max } \mathrm{nm}\left(\varepsilon \times 10^{4}\right):(\mathrm{MeOH} / \mathrm{DMF}, \mathrm{v}: \mathrm{v}, 9: 1) 264(1.1), 283(0.7)$, 293 (0.7); (pH 1) 254 (1.3), 288 (1.0); (pH 11) 259 (1.3), 274 (1.3); 1H-NMR (DMSO-d ${ }_{6}$ ): $\delta 3.69\left(\mathrm{~s}, 3 \mathrm{H}, \mathrm{CH}_{3}\right), 4.95(\mathrm{~s}, 2 \mathrm{H}$, $\left.\mathrm{CH}_{2}\right), 6.02\left(\mathrm{~s}, 2 \mathrm{H}, \mathrm{NH}_{2}\right), 6.32\left(\mathrm{~s}, 2 \mathrm{H}, \mathrm{NH}_{2}\right), 6.86(\mathrm{~d}, 2 \mathrm{H}, J=$ $8.6 \mathrm{~Hz}, \mathrm{Ar}-\mathrm{H}), 7.15(\mathrm{~d}, 2 \mathrm{H}, J=8.6 \mathrm{~Hz}, \mathrm{Ar}-\mathrm{H}), 10.80(\mathrm{~s}, 1 \mathrm{H}$, NII). Anal $\mathrm{C}_{13} \mathrm{H}_{14} \mathrm{~N}_{6} \mathrm{O}_{2}(\mathrm{C}, \mathrm{H}, \mathrm{N})$.

\section{8-Amino-9-(m-methylbenzyl)guanine $13 f$}

Compound $13 f$ was prepared in $89 \%$ yield using a procedure similar to that which afforded 13c. An analytical sample was prepared by recrystallization from a mixture of DMF/ $\mathrm{H}_{2} \mathrm{O}(\mathrm{v}: \mathrm{v}$, 1:1), mp: $>300^{\circ} \mathrm{C}$; IR (KBr): $3490,3390,3290,3150,2890$, $2740,1690,1620,1560,1460,1400,1375 \mathrm{~cm}^{-1}$; UV $\lambda_{\mathrm{nm}}$ $\left(\varepsilon \times 10^{4}\right):(\mathrm{MeOH} / \mathrm{DMF}, \mathrm{v}: \mathrm{v}, 9: 1) 261(1.4), 294(0.8) ;(\mathrm{pH} 1)$ 254 (1.3), 289 (1.0); (pH 11) 261 (1.2), 272 (1.2); ${ }^{1} \mathrm{H}-\mathrm{NMR}$ $\left(\mathrm{DMSO}-\mathrm{d}_{6}\right): \delta 2.24\left(\mathrm{~s}, 3 \mathrm{H}, \mathrm{CH}_{3}\right), 5.00\left(\mathrm{~s}, 2 \mathrm{H}, \mathrm{CH}_{2}\right), 6.13(\mathrm{~s}$, $\left.2 \mathrm{H}, \mathrm{NH}_{2}\right), 6.30$ (s, 2II, $\mathrm{NII}_{2}$ ), 6.94 (d, 1II, $J=7.61 \mathrm{IIz}$, Ar-II), $6.99(\mathrm{~s}, 1 \mathrm{H}, \mathrm{Ar}-\mathrm{H}), 705$ (d, $1 \mathrm{H}, J=7.61 \mathrm{~Hz}, \mathrm{Ar}-\mathrm{H}), 7.19$ $(\mathrm{t}, 1 \mathrm{H}, \mathrm{Ar}-\mathrm{H}), 10.69(\mathrm{~s}, 1 \mathrm{H}, \mathrm{NH})$. Anal $\mathrm{C}_{13} \mathrm{H}_{14} \mathrm{~N}_{6} \mathrm{O} \cdot 1 / 4 \mathrm{H}_{2} \mathrm{O}$ $(\mathrm{C}, \mathrm{H}, \mathrm{N})$.

\section{9-(p-Chlorobenzyl)guanine $14 a$}

A mixture of $7 \mathbf{a}(0.88 \mathrm{~g}, 3 \mathrm{mmol})$ in $95 \%$ formic acid $(5 \mathrm{ml})$ and formamide $(25 \mathrm{ml})$ was heated at reflux for $5 \mathrm{~h}$. The mixture was then poured onto ice/ $\mathrm{H}_{2} \mathrm{O}(150 \mathrm{ml})$. The resulting solid was collected by filtration and then washed with $\mathrm{H}_{2} \mathrm{O}$ $(15 \mathrm{ml})$. Recrystallization of the solid from a mixture of DMF/water (v:v, 1:1) furnished 14a $(0.76 \mathrm{~g}, 92 \%)$, mp: $336-$ $338^{\circ} \mathrm{C}$; UV $\lambda_{\max }$ nm $\left(\varepsilon \times 10^{4}\right)$ : $(\mathrm{MeOH}) 256(1.4) ;(\mathrm{pH} 1) 255$ (1.3), $277(0.9)$; (pH 11) 269 (1.2); 1H-NMR (DMSO-d 6 ): d $5.16\left(\mathrm{~s}, 2 \mathrm{H}, \mathrm{CH}_{2}\right), 6.46\left(\mathrm{~s}, 2 \mathrm{H}, \mathrm{NH}_{2}\right), 7.22(\mathrm{~d}, 2 \mathrm{H}, J=8.42 \mathrm{~Hz}$, Ar-H), 7.39 (d, 2H, $J=8.46 \mathrm{~Hz}, \operatorname{Ar}-\mathrm{H}), 7.77$ (s, 1H, H-8), $10.60(\mathrm{~s}, 1 \mathrm{H}, \mathrm{NH})$. Anal $\mathrm{C}_{12} \mathrm{H}_{10} \mathrm{CIN}_{5} \mathrm{O}(\mathrm{C}, \mathrm{H}, \mathrm{N})$.

\section{8-Bromo-9-(p-chlorobenzyl)guanine 15a}

Bromine $(1 \mathrm{ml})$ was added to a suspension of $14 \mathrm{a}(1.12 \mathrm{~g}$, $3.16 \mathrm{mmol})$ in $\mathrm{H}_{2} \mathrm{O}(50 \mathrm{ml})$. The mixture was allowed to stir at rt for $48 \mathrm{~h}$. The excess $\mathrm{Br}_{2}$ was removed in the fume hood. The red solid was collected by filtration and washed with water $(10 \mathrm{ml})$. The crude product was dissolved in a $10 \%$ aqueous $\mathrm{NaOH}$ solution and reprecipitated by the addition of glacial acetic acid to afford $15 \mathrm{a}(0.7 \mathrm{~g}, 49 \%)$, mp: $>300^{\circ} \mathrm{C}$; UV $\lambda_{\max } \mathrm{nm}$ $\left(\varepsilon \times 10^{4}\right):(\mathrm{MeOH}) 262$ (1.6); (pH 1) 260 (1.6); (pH 11) 273 (1.4); ${ }^{1} \mathrm{H}-\mathrm{NMR}$ (DMSO-d $): \delta 5.16\left(\mathrm{~s}, 2 \mathrm{H}, \mathrm{CH}_{2}\right), 6.62(\mathrm{~s}, 2 \mathrm{H}$, $\left.\mathrm{NH}_{2}\right), 7.20$ (d, $\left.2 \mathrm{H}, J=8.4 \mathrm{~Hz}, \mathrm{Ar}-\mathrm{H}\right), 7.42(\mathrm{~d}, 2 \mathrm{H}, J=8.4 \mathrm{~Hz}$, $\mathrm{Ar}-\mathrm{H}), 10.74(\mathrm{~s}, 1 \mathrm{H}, \mathrm{NH})$. Anal $\mathrm{C}_{12} \mathrm{H}_{9} \mathrm{BrClN}_{5} \mathrm{O}(\mathrm{C}, \mathrm{H}, \mathrm{N})$.

PNP inhibitory assay [9]

Substrate $\left[8-{ }^{14} \mathrm{C}\right]$ inosine was used at a specific activity of $22.5 \mathrm{mCi} / \mathrm{mmol}$. For $K_{\mathrm{m}}$ determinations, a fixed amount of diluted cell extract was incubated with variable amounts of radiolabeled substrate $(12.5-100 \mu \mathrm{M})$ and inorganic phosphate $(50 \mu \mathrm{M}) . K_{\mathrm{i}}$ determinations were performed with variable radiolabeled inosine concentrations $(12.5-100 \mu \mathrm{M})$, fixed inorganic phosphate $(50 \mu \mathrm{M})$ and variable inhibitor concentrations $(0.03-1.0 \mu \mathrm{M})$. All reactions were incubated for $10 \mathrm{~min}$ at $37^{\circ} \mathrm{C}$. Substrate and product (inosine and hypoxanthine, or guanosine and guanine, respectively) were separated by high voltage paper electrophoresis. The radiolabeled product of the reaction was visualized by UV light $(290 \mathrm{~nm})$, cut from the paper and counted in a toluene-based scintillation fluid in a Packard Tri-carb liquid scintillation spectrometer. Enzyme-free blank reactions were used as controls for all reactions. In all initial velocity determinations with or without inhibitor, not more than $15 \%$ of the substrate was converted to product. Double reciprocal plots of the initial velocity values versus the substrate concentrations were linear.

\section{Acknowledgments}

This investigation was supported by the UNDP/World Bank/WHO Special Programs for Research and Training in Tropical Diseases and Scientific Work group of Filariasis (ID 840398 and 870387). JWC received a fellowship from the National Science Council of the Republic of China in Taiwan.

\section{References}

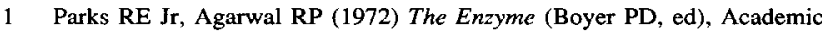
Press, NY, vol 7, 3rd edn, 483-514

2 Giblett ER, Ammann AJ, Wara DW, Sandman R, Diamond LK (1975) Lancet 1, 1010-1013

3 Kazmers IS, Mitchell BS, Daddona PE, Wotring LL, Townsend LB, Kelly WN (1981) Science 214, 1137-1139

4 Dadonna PE, Wiesmann WP, Milhouse W, Chern JW, Townsend LB, Hershfield MS, Webster HK (1986) J Biol Chem 261, 11667-11673

Sircar JC, Gilbertsen RB (1988) Drugs Future 13, 653- 668

6 Sanghvi YS, Hanna NB, Larson SB, Fujitaki JM, Willis RC, Smith RA, Robins RK, Revankar GR (1988) J Med Chem 31, 330-335

Halazy S, Ehrhard A, Danzin C (1991) J Am Chem Soc 113, 315-317

8 Shewach DS, Chem JW, Pillote KE, Townsend LB, Daddona PE (1986) Cancer Res 46, 519-523

9 Agarwal RP. Parks RE Jr (1971) J Biol Chem 246, 3763

10 Lewis AS, Glantz MD (1976) Biochemistry 15, 4451

11 Salamone SJ, Jordan F (1982) Biochemistry 21, 6382

12 Carlson JD, Fischer AG (1979) Biochem Biophys Acta 571, 21

13 Topliss JG (1972) J Med Chem 15, 1006-1011

14 Craig PN Burger's Medicinal Chemistry (Wolff ME, ed) John Wiley and Sons, NY, vol 1, 331

Topliss JG (1977) J Med Chem 20, 463-469

Boon WR, Leigh T (1951) J Chem Soc 1497-1501

Baker BR, Joseph JP, Schaub RE (1954) J Org Chem 19, 631-637

Stewart WE, Siddall TH III (1970) Chem Rev 70, 517-551

Curran DP, Kuo SC (1984) J Org Chem 49, 2063-2065

Pfleiderer W, Mengel R, Hemmerich P (1971) Chem Ber 104, 2273-2292

Chern JW, Lee HY, Wise DS, Townsend LB (1988) J Org Chem 53 5617-5622

22 Long RA, Robins RK, Townsend LB (1988) Synthetic Procedures in Nucleic Acid Chemistry (Zorbach WW, Tipson RS, eds) Interscience, NY, vol 1, 228-229

23 Noell CW, Robins RK (1962) J Med Chem 5, 558-588 